\title{
Research on the Value of Art Songs for Music Education Teaching of Preschool Education Major
}

\author{
Qu Defang
}

Xi’an University Xi’an, Shaanxi Province 710065

\author{
Keywords: Art song; Preschool Education; Music Teaching
}

\begin{abstract}
Art song pays attention to the literary nature of lyrics, the beauty of music and the connotation of piano, and it has an elegant style. Preschool music education is a teaching mode that integrates singing, music theory and solfeggio. It has important teaching value to put art song in preschool education, and putting art song in music education teaching of preschool education major is of important teaching value.

The preschool education major is a concrete practitioner of preschool education teaching in the front line, and music education is an important part of preschool education. The latter is related to the aesthetic quality of preschool practitioners and affects the personality and psychology of preschool children. The former Soviet music educator Dmitry Kabalevsky said, "The principle difference between the art curriculum and the technical curriculum is that any real work of art should have moral elements and aesthetic elements."

Art song has the essence beauty of art, which is suitable for music education teaching of preschool education major, but also suitable for the specific practice of preschool education major. For the music education teaching of preschool education major, art song has great advantages such as convenience, operability and acceptability.
\end{abstract}

\section{Artistic Features of art song}

Art song is an important genre in the history of music culture produced by composers, on the basis of the blending of music and literature with the help of literary artistic images such as drama and poetry. "Art song is the most popular type of music in the second half of the $19^{\text {th }}$ century."

Originated from folk songs, but art song is more poetic, exquisite and beautiful in content, structure, expression and technique than folk songs. It is free in form, with one-segment body and divertimento composed by multiple songs. Also, It has a wide range of subjects from folk songs to myths, with sincere melody, elegant music and elaborate lyrics. It is mostly based on the poems of famous poets, especially the lyric poetry, which presents the characteristics of elegance and delicacy.

Piano accompaniment occupies a very important position in art song. There is a complementary relationship between piano and vocal music. The piano is like singing to express the contents of lyrics, to depict scenes and to portray characters. Those that are not directly mentioned or suggestive in lyrics are expressed by piano, which forms a complete work of art with the vocal part. Some of the piano parts in art songs are not even called "piano accompaniment", but are marked with the subtitle "A poem written by... for vocal music and piano" , in order to show the piano's extraordinary status and role.

The art song is rich in content and delicate in intensity, with rich music technique from fff to ppp. The use of harmony and tone makes art song more artistic, and the characters are more delicate and expressive, "presenting almost the characters of the opera".

Due to its rich expressiveness and beautiful artistic structure, the art song has practical operability for cultivating students’ musical literacy and improving their knowledge and skills. 


\section{Situation of Music Teaching of Students Majored in Preschool Education}

Music teaching of preschool education major is a comprehensive course integrating music theory, solfeggio and ear training and vocal music. Music theory focuses on the theoretical knowledge of music, ear training trains the ear's sensitivity to sound, solfeggio converts visual symbols into sound, and vocal music focuses on how to sing beautifully. This comprehensive teaching integrating three courses is featured by complex content and rigorous time. For students, how to effectively teach the content of the three courses in an easily acceptable form will significantly improve the teaching effect.

Music teaching of students majored in preschool education has weak foundation in music. Most students do not have systematic music learning, cannot read music, and are not familiar with the usual rhythms. They even cannot distinguish the differences in song genres and do not have the awareness of style expression. In addition, they are indifferent to the connotation of music, such as melody, rhythm, harmony and texture. They are unfamiliar with the mastery of music style, the expression of charm and the treatment of art.

Based on the preschool educational and teaching situation, art song's teaching application is close to the students' actual level and preschool characteristics, and effectively improves the teaching effect of preschool music, making music theory, solfeggio and ear training, vocal music all organically linked together. This can not only take into account the three courses, but also make it easy for students to accept.

\section{The Value of Art Song for Music Education Teaching Of Preschool Education Major}

"Education is to cultivate the subject and pass on the culture, enabling the subject to grow by passing on the culture, and making the culture a vivid spirit in the subject”. The use of art song as the entry point of music education teaching of preschool education major can better integrate art, preschool and students to promote and grow.

The preschool education major's music class teaching can't be as sophisticated as a professional music course, but it can't be rough and random. Therefore, its course content is very important, and the course standpoint, selection and knowledge system are very important. The art song genre covers the music theory, solfeggio and ear training and singing, which not only serves the needs of preschool students' music teaching group lessons, but also is of great value. It is mainly reflected in:

\subsection{Meet the comprehensive characteristics of the preschool music teaching course}

Music teaching of preschool education major is a comprehensive course integrating music theory, solfeggio and ear training and vocal music. It combines three professional music teaching courses. Art song has the singing teaching of songs that include the singing techniques, expressiveness of songs, singing styles and other vocal music teaching contents, and also has the content of sight-reading practice and the application of music theory. It not only comprehensively reflects the three preschool music teaching courses, but also embodies and visualizes the boring teaching of music theory, solfeggio and ear training.

For students, the application of art song teaching makes the three comprehensive courses face the problems such as diverse contents, complexity, lack of unity and lack of systematic nature. However, it is effectively solved in the learning, singing and practice of art song, which makes the learning of music theory concrete, so that the learning of solfeggio and ear training is normalized, the learning of vocal music is standardized, and the preschool music teaching's comprehensive characteristics is satisfied.

Music teaching of preschool education major can't achieve in-depth implementation and professional study in the three comprehensive courses like professional music teaching, but it can't be watery. Therefore, it is necessary to combine three music courses with art song teaching so as to give consideration to both the comprehensive and the professional aspects, and take care of respective goals and purposes. 


\subsection{Improve the teaching effect of music teaching of preschool education major}

In the music teaching of preschool education major, students are poor at the edge of the three courses. It seems that the school has opened three courses, but in fact, it is uneasy for students to catch any one. Students always feel that it is difficult to understand the music theory; for solfeggio and ear training, the students always find it difficult to read; for ear training, it is difficult for them to distinguish the pitch interval of harmony; for vocal music part, it is difficult for them to understand the connotation of music, to grasp the main points of singing technique and to establish good singing habits. As a result, their ability to grasp and process songs is poor, producing unsatisfactory teaching results.

The teaching intervention of art song makes students no longer need to memorize the pitch interval and chord configuration, which visualizes the specific use of music speed, strength and expression terms. In the learning and singing of each song, it vividly visualizes these silent music theories, which greatly enhances students' interest in learning music and improves the teaching effect. In the song learning, practice and performance, it also significantly achieves the connection between technique and art, and improves the singing ability.

The rich songs, short lengths and subtle artistic connotations of art song have greatly developed the students' musical skills and artistic accomplishments. Despite the limited time and a wide variety, it condenses the essence of art, refines the teaching process, greatly improves the scientific, rational and practical nature of music teaching of preschool education major, and enhances the teaching effect.

\subsection{Be in line with the reality of preschool teaching and is conducive to students' future work.}

In Preschool music education teaching, through the specific study, analysis and practice, understand the basic knowledge of music, comprehend the appeal of music art, broaden the artistic vision, improve your music cultivation, students can follow the education after they go to work. The need for activities is to more fully select music works and creatively apply them to their work. At the same time, students can better transfer the conception and expression of music to the design of other educational activities according to their work needs, and better and more comprehensively do their own education and teaching activities.

Art song has a lot of different styles and genres. Through the continuous learning and accumulation of songs, we can solve the problem of weak basic knowledge of preschool education major students, fully understand the connotation of melody, rhythm and harmony art elements, and appreciate their charm. At the same time, continuous singing of songs is very helpful in improving their ability to sing and vocalize, improving their aesthetic standards and broadening their artistic horizons.

The exquisite structure, elegant style and diverse teaching of art song enhance the artistic practice of students and expand the artistic vision of students. In this way, the students may better play the role of music in the growth and development of young children in the future work, and change the situation of preschool music education teaching. This will be of great help to the future teaching work and will also make a lot of reserves for their future work.

\subsection{Better integrate the characteristics of preschool and music}

In the preschool teaching work, there are often many activities that require music, such as the dance arrangement, daily rhythm and the sports activities of young children. These activities involve the choice of music. The appropriate music should be selected for different activities, which requires teachers to have a large amount of music reserves, high music cultivation and strong musical ability.

If a preschool teacher only has certain musical skills, this is far from enough. Only those preschool teachers with comprehensive music quality can establish a good interactive platform for children to learn, understand, listen and love music. This will involve a series of knowledge about the aesthetics, taste, professional accumulation and professional comprehensive quality of music, as well as a series of practical music teaching activities such as singing and the teaching of music 
lessons. Therefore, the students majored in preschool education should combine the two characteristics of music major and early childhood teaching, that is, taking into account the characteristics of preschool major and not losing the rule of music major.

The art song teaching takes into account the above factors, and integrates music and literature more closely, achieving a high degree of unity between the language of music and the music of language. In this way, the basic knowledge of music can be better visualized in the form of sound, and the beneficial tastes and cultivation of students can be developed through the cultural inheritance of language. In addition, the art song teaching can also enhance students' artistic accomplishment and aesthetic taste, so that teaching, learning and application are closely combined and music is closely integrated with preschool, which is conducive to the cultivation of applied talents, and taking into account the characteristics of preschool and music.

\subsection{Stimulate the interest of students to learn and enrich the artistic quality of students.}

Students who study preschool education are selected through the college entrance examination. Due to exam-oriented education, many students do not have music lessons in senior middle school, and some students do not even learn music in junior middle school. In addition, students come from all over the country, and they have almost blank foundation of music. Most of the students' understanding of music comes from popular music. Their interest in systematic music learning is low, with poor music artistic quality. The involvement of art song enables students to feel the charm of classic music in beautiful songs, experience the artistic thoughts and aesthetic connotations of different music styles and genres, expand the horizon, and experience the delicate musical emotions.

As a vocal music genre, art song forms a small comprehensive art through the combination of music and literature. It embellishes students' artistic sentiments with unique aesthetic features, formal structures and expression styles. The beautiful combination of art song's piano accompaniment and lyrics is extremely unique to the cultivation of music and literature. By combining poetry and music, vocal music has a seductive aesthetic for the presentation of music, the expression of emotions and the harmony of sound and atmosphere, leaving a deep impression, making abstract concrete, enhancing the fun of learning and enriching the artistic accomplishment of students.

Art song is a mixed music genre composed of poetry, vocal music and instrumental music. It "starts from excellent literary poetry, and ends by the unique interpretation of music". At the same time, art song makes full use of the literary and musical music of lyrics to integrate the rich artistic connotation with classic culture, which is of great help to enhance artistic accomplishment.

The combination of art song's sound instrumental music is close and natural, and there is no abstraction of pure instrumental music, which enhances the closeness to music. It is characterized by delicate emotional expression, rich changes and appropriate subtle harmony of sound and atmosphere, thereby stimulating the beauty of music art. What's more, the clear and accurate biting and coherent smooth music language statements may directly arouse the interest of students, and simplify the boring process of interpretation, so that students are easy to operate and willing to accept. During this process-centered learning, the art song may enhance the fun of learning and perfect the depth and breadth of artistic accomplishment. Therefore, the art song is of great help to preschool music teaching.

\section{Acknowledgement}

Provincial-level project Research on Shaanxi Music Innovation in Cultural Information, $2018 Z 097$.

\section{References}

[1] Wei Huang, Hou Jinhong, Soviet Music Education, Shanghai Education Press, 1999.

[2] Paul Heny Lang, Translated by Yang Yandi, Music in Western Civilization, Guizhou People’s 
Publishing House, 2001.

[3] Mosco Carner, translated by Xiaolan, Hugo Wolf Songs, $39^{\text {th }}$ Book of BBC Music Guide, Shijiazhuang, Huashan Wenhua Press 1999.

[4] Liu Xiaodong, New Theory of Children's Education, Jiangsu Education Press, 1998.

[5] Yang Yandi, Humanistic Interpretation of Music, Shanghai Conservatory of Music Press, 2007. 